\title{
The importance of the CXCL12/ CXCR4 axis in therapeutic approaches to diabetes mellitus attenuation
}

\author{
Melita Vidaković*, Nevena Grdović, Svetlana Dinić, Mirjana Mihailović, \\ Aleksandra Uskoković and Jelena Arambašić Jovanović
}

Department of Molecular Biology, Institute for Biological Research, University of Belgrade, Belgrade, Serbia

OPEN ACCESS

Edited by:

Heidi Noels,

Institute for Molecular Cardiovascular

Research, Germany

Reviewed by:

Paul Proost,

KU Leuven, Belgium

Christopher G. Kevil,

LSU Health Sciences Center, USA

Valeria Sordi,

IRCCS San Raffaele Scientific

Institute, Italy

${ }^{*}$ Correspondence:

Melita Vidaković,

Department of Molecular Biology, Institute for Biological Research,

University of Belgrade, Bulevar

Despota Stefana 142,

Belgrade 10060, Serbia

melita@ibiss.bg.ac.rs

Specialty section:

This article was submitted to

Chemoattractants, a section of the journal Frontiers in Immunology

Received: 04 May 2015

Accepted: 23 July 2015

Published: 07 August 2015

Citation:

Vidaković M, Grdović N, Dinić S,

Mihailović M, Uskoković A and Arambašić Jovanović J (2015) The importance of the CXCL12/CXCR4

axis in therapeutic approaches to

diabetes mellitus attenuation.

Front. Immunol. 6:403.

doi: 10.3389/fimmu.2015.00403
The pleiotropic chemokine ( $\mathrm{C}-\mathrm{X}-\mathrm{C}$ motif) ligand 12 (CXCL12) has emerged as a crucial player in several diseases. The role of CXCL12 in diabetes promotion and progression remains elusive due to its multiple functions and the overwhelming complexity of diabetes. Diabetes is a metabolic disorder resulting from a failure in glucose regulation due to $\beta$-cell loss and/or dysfunction. In view of its ability to stimulate the regeneration, proliferation, and survival of $\beta$-cells, as well as its capacity to sustain local immune-isolation, CXCL12 has been considered in approaches aimed at attenuating type 1 diabetes. However, a note of caution emerges from examinations of the involvement of CXCL12 in the development of diabetes and its complications, as research data indicate that CXCL12 displays effects that range from protective to detrimental. Therefore, as a beneficial effect of CXCL12 in one process could have deleterious consequences in another, a more complete understanding of CXCL12 effects, in particular its functioning in the cellular microenvironment, is essential before CXCL12 can be considered in therapies for diabetes treatment.

Keywords: CXCL12, CXCR4, CXCR7, diabetes mellitus, diabetic complications, pancreatic $\beta$-cells

\section{Introduction}

The worldwide prevalence of diabetes has increased six-fold over the past 20 years, with diabetes assuming the proportions of an epidemic. Therefore, research devoted toward improving the steps that could be undertaken in the prevention and treatment of diabetes and its complications is a scientifically and socially significant task. Diabetes mellitus is a complex metabolic disorder that is presented in two major forms, type 1 diabetes (T1D) and the more common type 2 diabetes (T2D). While these conditions have different etiologies, both types of diabetes are characterized by hyperglycemia resulting either from insufficient insulin levels as in T1D, or by an insensitivity of target cells to insulin as in T2D. In T1D, hyperglycemia occurs as a result of destruction of insulin-producing pancreatic $\beta$-cells in an autoimmune process. T2D is a metabolic disease characterized by $\beta$-cell dysfunction and peripheral insulin resistance. Genetic predisposition and environmental factors, such as diet, physical inactivity, and viral infections contribute to the etiology of diabetes. Early exposure to hyperglycemia predisposes individuals to the development of diabetic complications, a phenomenon which is referred to as "metabolic memory" (1). At present, diabetes management is focused on lowering hyperglycemia and treating its pathological consequences, rather than its initial triggers. 


\section{CXCL12 and its Receptors}

Currentresearch has positioned CXCL12 as an important molecule in potential treatment of diabetes and its complications. CXCL12 belongs to the CXC group of chemokines. It is a potent chemoattractant involved in angiogenesis, leukocyte trafficking, cancer, inflammatory disorders, atherosclerosis, and HIV pathology $(2,3)$. CXCL12 is a ligand for two transmembrane receptors: CXCR4 and CXCR7 $(4,5)$. Interaction between CXCL12 and its receptor CXCR4 induces downstream signaling involved in chemotaxis, cell survival, proliferation, increase in intracellular calcium, and gene transcription (3). CXCR7 is an atypical chemokine receptor that does not signal through the canonical G-protein pathway. CXCL12 binds CXCR7 with even higher affinity than CXCR4. CXCR7/CXCL12 interaction triggers CXCR7 association with $\beta$-arrestin 2 and CXCL12/CXCR7 internalization, implying capability of CXCR7 to decrease the level of CXCL12 from the surroundings (6). The observed promotion of cell survival, adhesion, and tumor growth by CXCR7 points to signaling pathways that lie downstream of this receptor (7). This may be in correlation with its ability to heterodimerize with CXCR4 and regulate CXCR4/ CXCL12-mediated processes. The role of CXCR7 in mediating the anti-apoptotic effect of CXCL12 has been documented (8). CXCR7 has also emerged as a determinant of autoimmunity and $\beta$-cell destruction which underlies diabetic progression (9).

\section{The Role of CXCL12/CXCR4 Axis in Diabetes Pathophysiology}

\section{Type 1 Diabetes}

Type 1 diabetes is an autoimmune disease triggered by environmental factors in genetically susceptible persons. In T1D, pancreatic $\beta$-cells are targeted by the individual's own immune system resulting in reduced or complete elimination of insulin production. Discouraging, long-term studies of islet transplantation stress the need for new strategies to counteract autoimmunity, and CXCL12 has emerged as a key molecule in this process. CXCL12 plays a particularly important role in directing $\mathrm{T}$ cell migration and therefore in immune processes. Recruitment of autoreactive $\mathrm{T}$ cells into pancreatic islets leads to inflammation (referred to as insulitis) that initiates T1D development. Several reports have revealed that neutralization of CXCL12 inhibits insulitis and diabetes development $(10,11)$. It was proposed that retention of regulatory $\mathrm{T}$ cells (Tregs) in the bone marrow by CXCL12 disturbs the balance of $\mathrm{T}$ cells in favor of autoreactive $\mathrm{T}$ cells, which intensifies disease progress. However, a reverse effect of CXCL12 inhibition was reported by Aboumarad et al. who showed that a population of CXCR4+ T cells attracted by CXCL12 protects recipient mice from the adoptive cell transfer of diabetes (12). The beneficial effects of CXCL12 could be explained by several properties specific to this chemokine. CXCL12 induces bi-directional movement of $\mathrm{T}$ cells, toward lower concentration and away from higher CXCL12 concentration (13). CXCL12 also exerts a chemorepulsive effect on diabetogenic $\mathrm{T}$ cells, while mediating firm adhesion of normal T cells (14). Moreover, CXCL12 expression in islets was shown to cause the selective repulsion of autoreactive $\mathrm{T}$ cells and retention of Tregs at the site (15). Tregs play a crucial role in suppressing autoimmunity and data support their relevance in T1D pathogenesis (16). It was reported that pancreatic lymph nodes (PLNs) of non-obese diabetic (NOD) mice lack Tregs, while the recovery of euglycemia in these mice was associated with the restoration of the Treg population in PLNs (17). The absence of Tregs correlates with the locally decreased expression of CXCL12, suggesting that improved function of the CXCL12/CXCR4 axis and subsequent retention of Tregs in the PLNs could serve as the basis for an alternative therapeutic approach for treating T1D. Selective repulsion of autoreactive $\mathrm{T}$ cells and attraction of Tregs have been proposed as a mechanism for a recently reported novel strategy in islet transplantation. It has been shown that immunemediated rejection of transplanted islets could be delayed by their local immune-isolation achieved through coating or encapsulation of islets with CXCL12, thus excluding the need for systemic immunosuppression (18). Despite the evidence importance of this finding for T1D treatment, it should be noted that local immunosuppression achieved through CXCL12 has also been observed in cancer models where this mechanism protects cancer cells from immune attack (19).

\section{Type 2 Diabetes}

Type 2 diabetes is a metabolic disorder characterized by insulin resistance in adipose tissue, liver and skeletal muscle, and defective pancreatic insulin secretion. Experimental and clinical data describe diabetes as a chronic inflammatory disease (20). More than 20 years ago, it was shown that the pro-inflammatory cytokine TNF- $\alpha$ was capable of inducing insulin resistance (21). It is now known that the plasma levels of pro-inflammatory cytokines, such as TNF- $\alpha$, IL- 6 or IL- $1 \beta$, and chemokines are elevated in T2D patients, while in vivo studies have revealed that inhibition of key inflammatory cytokines protects rodents from insulin resistance (22). The inflammatory cytokines promote insulin resistance by interfering with insulin signaling through activation of JNK kinase and NFKB pathways (23). Pancreatic $\beta$-cells respond to insulin resistance by increasing insulin secretion. However, when $\beta$-cells fail to compensate for increased insulin demands, T2D develops.

Chronic low levels of inflammation in the pancreas and insulin-responsive tissues of diabetics are accompanied by infiltration of lymphocytes and macrophages. The latter process is associated with a switch from an anti- to a pro-inflammatory profile. Namely, diabetes is linked to a disturbed balance between pro-inflammatory (Th1 and Th17) and anti-inflammatory (Th2 and Tregs) subsets of $\mathrm{T}$ cells in favor of the pro-inflammatory phenotype. As a result, Th1 and Th17 promote the polarization of M1 macrophages, which are the main producers of pro-inflammatory cytokines (24). CXCL12 has a controversial role in inflammation, as a result of its ability to orchestrate the trafficking of a variety of immune cells. Based on the reports describing CXCL12-promoted recruitment of immune cells to inflamed tissues in autoimmune diseases such as rheumatoid arthritis (RA) and lupus erythematosus in lung inflammation and inflammatory bowel disease (25), CXCL12 has been proposed to have a pro-inflammatory role. Also, CXCL12 recruits monocytes into adipose tissue, which after differentiation secrete pro-inflammatory cytokines in obesity. It was suggested that the 
CXCL12/CXCR4 axis induces M1 macrophage accumulation, subsequent inflammatory cytokine production, and finally insulin resistance (26). However, CXCL12 was also found to possess an anti-inflammatory role by mediating $\mathrm{T}$ cell polarization toward Tregs, and by stimulating IL-10 production in anti-inflammatory M2 macrophages (27). Moreover, CXCL12 promotes migration of monocytes and their polarization toward the M2 phenotype (28), which points to the potential role of CXCL12 in reducing inflammation in diabetes. Once again, we should be aware that promotion of the anti-inflammatory Treg/M2 phenotype by CXCL12 is part of the mechanism involved in suppression of anti-tumor immunity mediated by this chemokine (29).

Given the strong correlation between inflammation and T2D, anti-inflammatory strategies for T2D treatment have been proposed and some have been clinically tested. Encouraging results were observed with salsalate, an inhibitor of the NF- $\kappa B$ pathway, and IL-1 $\beta$ antagonists. Potential targeting of CXCL12 for T2D treatment requires additional studies and a better understanding of the role of CXCL12 in T2D and inflammation.

\section{Potential Utilization of the CXCL12/CXCR4 Axis in Diabetes Management Through Promotion of Pancreatic $\beta$-Cell Differentiation, Regeneration, and Survival}

Current limitations in diabetes treatment have stimulated efforts toward $\beta$-cell replacement therapy. Preservation of $\beta$-cell mass, stimulation of $\beta$-cell differentiation from embryonic stem cells (ESCs), regeneration of the impaired endocrine pancreas from remaining $\beta$-cells, and cellular reprograming of other endocrine or exocrine cell types in pancreas could provide a long-term solution in diabetes treatment (30-32). This strategy requires understanding of the molecular mechanisms that control $\beta$-cell maturation, growth, and survival.

\section{The CXCL12/CXCR4 Axis in $\beta$-Cell Differentiation and Regeneration}

CXCL12/CXCR4 signaling is crucial for $\beta$-cell differentiation and pancreatic islet genesis (31). CXCL12 is expressed in the gut endoderm and attracts CXCR4 expressing angioblasts which induce pancreatic and duodenal homeobox 1 (Pdx1) expression in the pre-pancreas region (33). Pdx1 plays a key role in the expression of neurogenin 3 (Ngn3) which is essential for the formation of all islet cell types (34). During human fetal $\beta$-cell development, CXCR4 is necessary for the in vivo differentiation of islet-like clusters into $\beta$-cells while CXCL12 directs the proliferation of epithelial endocrine precursors through activation of phosphatidyl inositol (PI)-3 and Akt kinases (31). Expression of interferon (IFN) $\gamma$, which is under the control of the insulin promoter, promotes ductal hyperplasia and regeneration of new islets in the pancreas of transgenic mice (35), providing an excellent model for studding pancreas regeneration. When NOD mice were used as an IFN $\gamma$ transgenic model, their pancreas displayed three- and four-fold elevated expression of CXCL12 and CXCR4, respectively, in comparison to non-transgenic NOD mice (36).
CXCL12 expression in IFN $\gamma$-NOD mice stimulated pancreatic ductal cell migration and activation of the Akt, Src, and extracellular signal regulated protein kinase (ERK1/2) in duct cells, revealing the essential role of CXCL12 in their survival, proliferation, and migration during pancreatic regeneration. These insights could help in developing new therapeutic protocols for stimulating the differentiation of pancreatic stem cells into $\beta$-cells, proliferation of existing $\beta$-cells and transdifferentiation of particular cell types in diabetic patients $(31,32,37)$. Furthermore, in vitro treatment of human ESCs with appropriate signals could direct their differentiation into $\beta$-cells that could be transplanted in diabetic patients.

\section{The CXCL12/CXCR4 Axis in $\beta$-Cell Survival}

Diabetes-related studies have provided evidence for an important role of CXCL12 in anti-apoptotic and anti-necrotic protection of $\beta$-cells from diabetogenic agents. Transgenic mice overexpressing CXCL12 in $\beta$-cells are protected from streptozotocin (STZ)induced diabetes via activation of Akt kinase (38). CXCL12stimulated Akt signaling activates anti-apoptotic signals in $\beta$-cells through increased expression of the anti-apoptotic B cell lymphoma $2(\mathrm{Bcl}-2)$ protein and anti-apoptotic phosphorylation of the proapoptotic Bcl-2-associated death (BAD) protein. CXCL12-mediated induction of Akt activity also promotes activation and stabilization of beta-catenin/transcription factor 7-like 2 (TCF7L2) that contributes to the survival of isolated islets and INS-1 cells (39). Activation of the CXCL12/CXCR4 axis by STZ, cytokines and in thapsigargin injury of human and mouse islets promotes intra-islet GLP-1 production and enhances $\beta$-cell survival (40). It has been proposed that the paracrine action of CXCL12 from $\beta$-cells activates Akt in adjacent $\alpha$-cells, promoting their proliferation and production of GLP-1 instead of glucagon. CXCL12 and GLP-1 signal from $\alpha$-cells together control the growth and viability of $\beta$-cells. These findings raise the possibility that the anti-apoptotic/prosurvival CXCL12 and progrowth GLP-1 signaling act either additively or synergistically to conserve or possibly enhance $\beta$-cell mass in response to injury.

CXCL12 overexpression considerably improves insulin expression and viability of isolated rat islet cells and Rin-5F pancreatic $\beta$-cells after hydrogen peroxide treatment (41). CXCL12 overexpression in pancreatic cells switches hydrogen peroxideinduced cell death from the necrotic to the apoptotic pathway through Akt kinase-mediated reduction of poly(ADP-ribose) polymerase-1 (PARP-1) activity (Figure 1). These findings are in correlation with the documented role of PARP-1 in necrotic cell death (42) and with the observation that pharmacological inhibition or genetic deletion of PARP-1 protects animals against chemically induced and spontaneous diabetes development (43). The anti-necrotic effect of CXCL12 could prevent an additional pro-inflammatory burden of $\beta$-cells provoked by necrosis and could therefore be used for diabetes treatment.

\section{Transcriptional Regulation of the CXCL12 Gene}

Considering the involvement of CXCL12 in $\beta$-cell differentiation, growth, and survival, an understanding of CXCL12 transcriptional regulation offers possibility to improve $\beta$-cell mass in diabetes. PARP-1 is involved in rat CXCL12 gene (Cxcl12) 


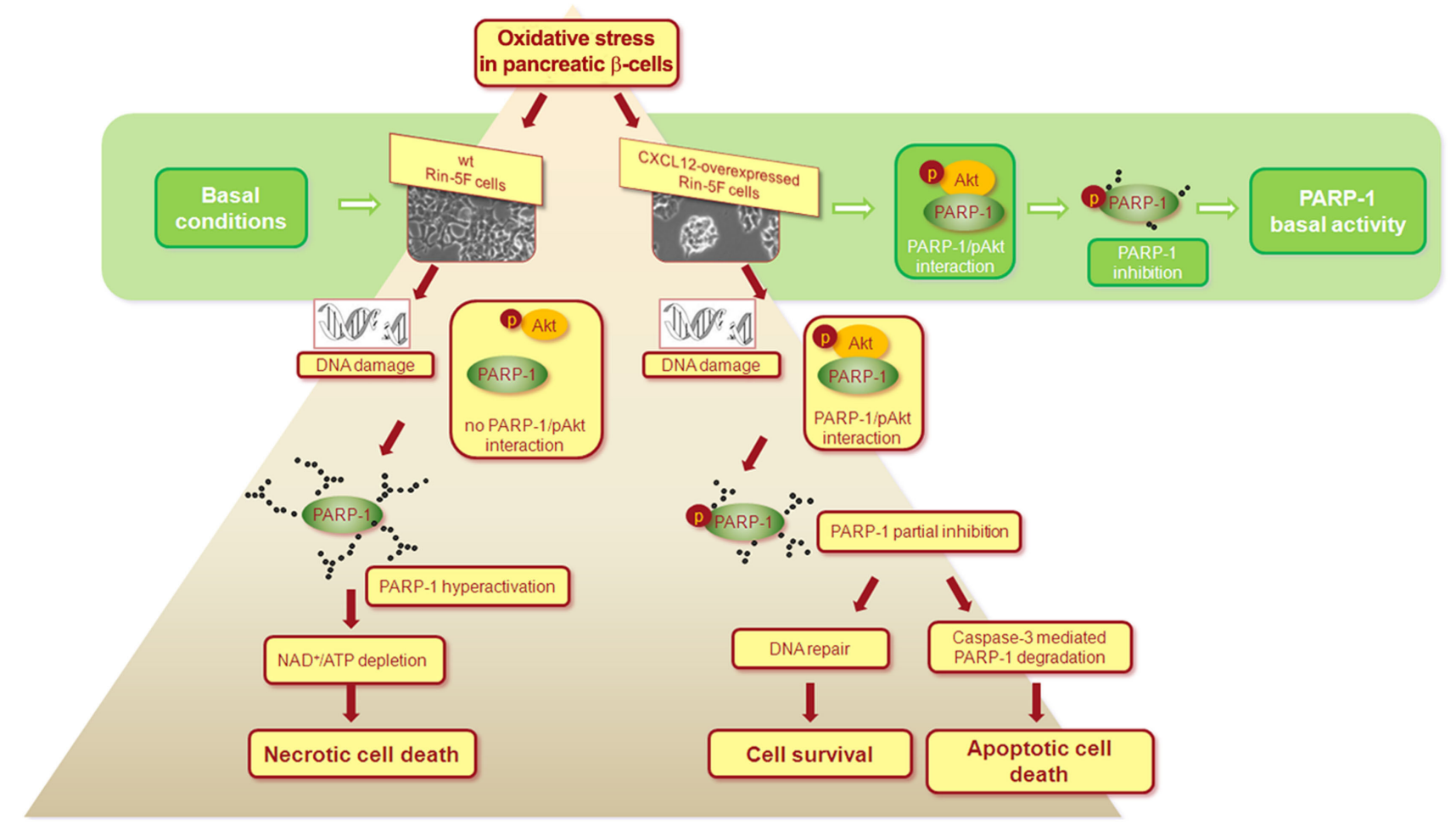

FIGURE 1 | Proposed mechanism of the CXCL12/Akt-mediated anti-necrotic effect that leads to pancreatic $\boldsymbol{\beta}$-cells survival. Under basal conditions, interaction between activated Akt (pAkt) and PARP-1 leads to PARP-1 phosphorylation that results in partial inhibition of PARP-1 in wild type (wt) and CXCL12 overexpressing Rin-5F cells. After hydrogen peroxide-induced oxidative stress and in response to severe DNA damage in wt cells, the loss of pAkt-PARP-1 interaction allows PARP- 1 hyperactivation, followed by extensive PARP-1 auto-poly(ADP-ribosyl)ation, NAD+ and ATP depletion, and final necrotic cell death. In CXCL12 overexpressing cells, pAkt-PARP-1 interaction persists after hydrogen peroxide treatment, maintaining partial inhibition of PARP-1. Consequently, cellular energy depletion is prevented and a switch from the necrotic to the apoptotic cell death is ensured. With CXCL12-mediated suppression of PARP-1 overactivation in stress conditions, cell still operates with the active PARP-1 that is essential player in many cellular processes. The mechanism is based on the findings presented in Ref. (41). downregulation during the early stage of STZ-induced oxidative stress (44). During later stages of oxidative stress and intensive pancreatic $\beta$-cell injury, Cxcl12 expression is upregulated by Yin Yang 1 (YY1). Multiple protein-protein interactions between $\mathrm{C} / \mathrm{EBP} \alpha, \mathrm{C} / \mathrm{EBP} \beta$, STAT3, p53, FOXO3a, and HMG I/Y transcription factors that bind to the $\mathrm{Cxcl12}$ promoter in the rat pancreatic Rin-5F cell line suggest that multi-subunit protein complexes are responsible for the regulation of $\mathrm{Cxcl12}$ transcription (44). Targeted stimulation or suppression of specific transcription factors involved in the regulation of genes engaged in the proper functioning of $\beta$-cells could improve therapeutic approaches in diabetes.

\section{The Controversial Role of CXCL12 in Diabetic Complications}

Along with the promotion of cell survival, the biological effects of CXCL12, such as angiogenesis induction and recruitment of bone marrow-derived progenitor cells suggest that this chemokine assumes a central position in tissue repair and regeneration. Since diabetes is accompanied by dysfunction and life-threatening damage of several organs, the potential of CXCL12 to create a microenvironment that supports repair processes is particularly important. Indeed, CXCL12 accelerates wound healing in diabetes by recruiting endothelial progenitor cells (EPCs) and through improved angiogenesis $(45,46)$. However, the same injury response mechanisms could also promote disease progression, as in diabetic retinopathy, which starts with damage to small blood vessels in the eye and leads to reduced blood flow and ischemia. The ischemia promotes aberrant neovascularization that destroys the normal retinal architecture, causing impaired vision. In agreement with the fact that the expression of CXCL12 is controlled by hypoxia-inducible factor-1 (47), the level of CXCL12 increases as diabetic retinopathy progresses and contributes to angiogenesis by recruiting EPCs to the site of vascular injury (48). Blocking the function of CXCL12 prevents neovascularization and progression of proliferative retinopathy.

Diabetic nephropathy is characterized by the development of albuminuria with a subsequent decline in glomerular filtration rate, usually followed by failure of renal function. CXCL12 expression in the kidney increases during acute renal failure, resulting in homing of progenitor cells to the injured kidney (49). Although CXCL12 is considered as one of the major mediators involved in kidney repair after ischemic acute renal failure, data regarding the role of this chemokine in diabetic nephropathy 
are limited. A study on the mouse model of T2D revealed that CXCL12 contributes to glomerulosclerosis, podocyte loss, and albuminuria, implicating the pathogenic role of CXCL12 in diabetic nephropathy (50). The same group proposed a novel strategy for the prevention of glomerulosclerosis in T2D. This is based on the protective effect of dual chemokine CCL2-CXCL12 blockage: inhibition of CCL2-mediated glomerular leukocyte recruitment and CXCL12-mediated loss of podocytes (51).

Diabetes dramatically increases the risk of various cardiovascular problems, including coronary artery disease with myocardial infarction and atherosclerosis (52). Although the importance of CXCL12 in cardiovascular disease has been intensively studied, current findings once again suggest a double-edged role of this chemokine in ischemic heart and atherosclerosis (53). Since this issue has been extensively reviewed elsewhere in Ref. (53), it will not be considered here in more detail. It is worth mentioning that genome-wide association studies revealed a significant association of two SNPs downstream of the CXCL12 gene with cardiovascular disease (54).

The general conclusion regarding the role of CXCL12 in diabetic complications is that CXCL12 walks a thin line between protective and detrimental effects. Therapies that rely on either promotion of CXCL12 or blocking of its activity have been suggested for a variety of conditions. The above-mentioned findings indicate that CXCL12-based therapy should be used with extreme caution and by precise targeting of CXCL12 action to specific tissue (Table 1). Proper functioning of the immune system provides a balance between protection from pathogens and tissue damage, and between autoimmunity and cancer suppression. Disturbance of this balance might be beneficial in one process, while at the same time detrimental in another.

\section{Conclusion}

The role of CXCL12 in diabetes is very complex. For a better understanding of the biological effects of CXCL12, additional studies are needed to clarify several issues. As has already been mentioned, aside from CXCR4, CXCL12 also binds to its second receptor CXCR7, whose downstream signaling is elusive. The reported heterodimerization of these receptors has introduced additional complexity to CXCL12 signaling (55). CXCR7 also binds CXCL11 (56), while CXCR4 has been shown to be a receptor for the cytokine MIF and chemokine CXCL14 $(57,58)$. Therefore, the biological functions of CXCL12 must be considered in the

\section{References}

1. Pirola L, Balcerczyk A, Okabe J, El-Osta A. Epigenetic phenomena linked to diabetic complications. Nat Rev Endocrinol (2010) 6:665-75. doi:10.1038/ nrendo. 2010.188

2. Broxmeyer HE, Cooper S, Kohli L, Hangoc G, Lee Y, Mantel C, et al. Transgenic expression of stromal cell-derived factor-1/CXC chemokine ligand 12 enhances myeloid progenitor cell survival/antiapoptosis in vitro in response to growth factor withdrawal and enhances myelopoiesis in vivo. J Immunol (2003) 170:421-9. doi:10.4049/jimmunol.170.1.421

3. Teicher BA, Fricker SP. CXCL12 (SDF-1)/CXCR4 pathway in cancer. Clin Cancer Res (2010) 16:2927-31. doi:10.1158/1078-0432.CCR-09-2329

4. Balabanian K, Lagane B, Infantino S, Chow KYC, Harriague J, Moepps $\mathrm{B}$, et al. The chemokine SDF-1/CXCL12 binds to and signals through the
TABLE 1 | Yin-Yang nature of CXCL12 in diabetic complications.

Effects of activated CXCL12/CXCR4 axis
(in a mouse model system)
Accelerates wound healing in diabetes, improves
angiogenesis
Promotes diabetic retinopathy, contributes to
angiogenesis via recruitment of EPCs to the site
of vascular injury
Improves diabetes progression in NOD mice by
sequestering Tregs in the bone marrow, which
disturbs the balance in favor of autoreactive T cells
Prevents insulitis and autoimmune diabetes via
recruitment of Th2-type cells to the pancreas of
NOD mice
Mediates kidney repair by homing of progenitor
cells to the injured kidney in acute renal failure
Contributes to progression of diabetic
nephropathy through involvement in
glomerulosclerosis, podocyte loss and
albuminuria
Induces M1 macrophage accumulation in
adipose tissue which leads to secretion of pro-
inflammatory cytokines in obesity, associated with
insulin resistance

Balanced (1) CXCL12 expression and distribution is indispensable for the final outcome of physiological action that can produce either protective $(\bullet)$ or detrimental effects (9) during diabetes onset and in diabetic complications.

context of a specific microenvironment, taking into account the site of CXCL12 expression, the expression of other chemokines, and all receptors on target cells. A complete understanding of the complex CXCL12 network is a prerequisite for the safe application of CXCL12-based therapy in diabetes.

\section{Acknowledgments}

This work was supported by the Ministry of Education, Science and Technological Development of the Republic of Serbia, Grant No. 173020. We are very grateful to Professor Dr. Ludwig Wagner (Department of Internal Medicine III, Medical University of Vienna, Vienna, Austria) for all scientific help, suggestions, and unlimited support. We are grateful to Dr. Goran Poznanović for the English editing of the manuscript and scientific discussion. This work is part of COST Action CM1406.

orphan receptor RDC1 in T lymphocytes. J Biol Chem (2005) 280:35760-6. doi:10.1074/jbc.M508234200

5. Bleul CC, Farzan M, Choe H, Parolin C, Clark-Lewis I, Sodroski J, et al. The lymphocyte chemoattractant SDF-1 is a ligand for LESTR/fusin and blocks HIV-1 entry. Nature (1996) 382:829-33. doi:10.1038/382829a0

6. Berahovich RD, Zabel BA, Lewen S, Walters MJ, Ebsworth K, Wang Y, et al. Endothelial expression of CXCR7 and the regulation of systemic CXCL12 levels. Immunology (2014) 141:111-22. doi:10.1111/imm.12176

7. Sanchez-Martin L, Sanchez-Mateos P, Cabanas C. CXCR7 impact on CXCL12 biology and disease. Trends Mol Med (2013) 19:12-22. doi:10.1016/j. molmed.2012.10.004

8. Bakondi B, Shimada IS, Peterson BM, Spees JL. SDF-1alpha secreted by human CD133-derived multipotent stromal cells promotes neural progenitor cell survival through CXCR7. Stem Cells Dev (2011) 20:1021-9. doi:10.1089/scd.2010.0198 
9. Fallahi P, Corrado A, Di Domenicantonio A, Frenzilli G, Antonelli A. CXCR3, CXCR5, CXCR6, and CXCR7 in diabetes. Curr Drug Targets (2014).

10. Leng Q, Nie Y, Zou Y, Chen J. Elevated CXCL12 expression in the bone marrow of NOD mice is associated with altered $\mathrm{T}$ cell and stem cell trafficking and diabetes development. BMC Immunol (2008) 9:51. doi:10.1186/1471-2172-9-51

11. MatinK,Salam MA,AkhterJ,HanadaN,SenpukuH.Roleofstromal-cellderived factor-1 in the development of autoimmune diseases in non-obese diabetic mice. Immunology (2002) 107:222-32. doi:10.1046/j.1365-2567.2002.01478.x

12. Aboumrad E, Madec AM, Thivolet C. The CXCR4/CXCL12 (SDF-1) signalling pathway protects non-obese diabetic mouse from autoimmune diabetes. Clin Exp Immunol (2007) 148:432-9. doi:10.1111/j.1365-2249.2007.03370.x

13. Poznansky MC I, Olszak T, Foxall R, Evans RH, Luster AD, Scadden DT. Active movement of T cells away from a chemokine. Nat Med (2000) 6:543-8. doi:10.1038/75022

14. Sharp CD, Huang M, Glawe J, Patrick DR, Pardue S, Barlow SC, et al. Stromal cell-derived factor-1/CXCL12 stimulates chemorepulsion of NOD/LtJ T-cell adhesion to islet microvascular endothelium. Diabetes (2008) 57:102-12. doi:10.2337/db07-0494

15. Papeta N, Chen T, Vianello F, Gererty L, Malik A, Mok YT, et al. Longterm survival of transplanted allogeneic cells engineered to express a $\mathrm{T}$ cell chemorepellent. Transplantation (2007) 83:174-83. doi:10.1097/01. tp.0000250658.00925.c8

16. Bluestone JA, Tang Q, Sedwick CE. T regulatory cells in autoimmune diabetes: past challenges, future prospects. J Clin Immunol (2008) 28:677-84. doi:10.1007/s10875-008-9242-z

17. Nti BK, Markman JL, Bertera S, Styche AJ, Lakomy RJ, Subbotin VM, et al. Treg cells in pancreatic lymph nodes: the possible role in diabetogenesis and beta cell regeneration in a T1D model. Cell Mol Immunol (2012) 9:455-63. doi:10.1038/cmi.2012.36

18. Chen T, Yuan J, Duncanson S, Hibert ML, Kodish BC, Mylavaganam G, et al. Alginate encapsulant incorporating CXCL12 supports long-term allo- and xenoislet transplantation without systemic immune suppression. Am J Transplant (2015) 15:618-27. doi:10.1111/ajt.13049

19. Righi E, Kashiwagi S, Yuan J, Santosuosso M, Leblanc P, Ingraham R, et al. CXCL12/CXCR4 blockade induces multimodal antitumor effects that prolong survival in an immunocompetent mouse model of ovarian cancer. Cancer Res (2011) 71:5522-34. doi:10.1158/0008-5472.CAN-10-3143

20. Donath MY, Shoelson SE. Type 2 diabetes as an inflammatory disease. Nat Rev Immunol (2011) 11:98-107. doi:10.1038/nri2925

21. Hotamisligil GS, Shargill NS, Spiegelman BM. Adipose expression of tumor necrosis factor-alpha: direct role in obesity-linked insulin resistance. Science (1993) 259:87-91. doi:10.1126/science.7678183

22. Jagannathan-Bogdan M, McDonnell ME, Shin H, Rehman Q, Hasturk H, Apovian CM, et al. Elevated proinflammatory cytokine production by a skewed T cell compartment requires monocytes and promotes inflammation in type 2 diabetes. J Immunol (2011) 186:1162-72. doi:10.4049/jimmunol.1002615

23. Shoelson SE, Lee J, Goldfine AB. Inflammation and insulin resistance. J Clin Invest (2006) 116:1793-801. doi:10.1172/JCI29069C1

24. Esser N, Legrand-Poels S, Piette J, Scheen AJ, Paquot N. Inflammation as a link between obesity, metabolic syndrome and type 2 diabetes. Diabetes Res Clin Pract (2014) 105:141-50. doi:10.1016/j.diabres.2014.04.006

25. Werner L, Guzner-Gur H, Dotan I. Involvement of CXCR4/CXCR7/CXCL12 interactions in inflammatory bowel disease. Theranostics (2013) 3:40-6. doi:10.7150/thno. 5135

26. Kim D, Kim J, Yoon JH, Ghim J, Yea K, Song P, et al. CXCL12 secreted from adipose tissue recruits macrophages and induces insulin resistance in mice. Diabetologia (2014) 57:1456-65. doi:10.1007/s00125-014-3237-5

27. Karin N. The multiple faces of CXCL12 (SDF-1alpha) in the regulation of immunity during health and disease. J Leukoc Biol (2010) 88:463-73. doi:10.1189/jlb.0909602

28. Beider K, Bitner H, Leiba M, Gutwein O, Koren-Michowitz M, Ostrovsky O, et al. Multiple myeloma cells recruit tumor-supportive macrophages through the CXCR4/CXCL12 axis and promote their polarization toward the M2 phenotype. Oncotarget (2014) 5:11283-96.

29. Zou W, Machelon V, Coulomb-L'Hermin A, Borvak J, Nome F, Isaeva T, et al. Stromal-derived factor-1 in human tumors recruits and alters the function of plasmacytoid precursor dendritic cells. Nat Med (2001) 7:1339-46. doi:10.1038/ nm1201-1339
30. Bouwens L, Houbracken I, Mfopou JK. The use of stem cells for pancreatic regeneration in diabetes mellitus. Nat Rev Endocrinol (2013) 9:598-606. doi:10.1038/nrendo.2013.145

31. Kayali AG, Lopez AD, Hao E, Hinton A, Hayek A, King CC. The SDF-1alpha/ CXCR4 axis is required for proliferation and maturation of human fetal pancreatic endocrine progenitor cells. PLoS One (2012) 7:e38721. doi:10.1371/ journal.pone. 0038721

32. Weir GC, Cavelti-Weder C, Bonner-Weir S. Stem cell approaches for diabetes: towards beta cell replacement. Genome Med (2011) 3:61. doi:10.1186/gm277

33. Katsumoto K, Kume S. The role of CXCL12-CXCR4 signaling pathway in pancreatic development. Theranostics (2013) 3:11-7. doi:10.7150/thno.4806

34. Oliver-Krasinski JM, Kasner MT, Yang J, Crutchlow MF, Rustgi AK, Kaestner $\mathrm{KH}$, et al. The diabetes gene Pdx1 regulates the transcriptional network of pancreatic endocrine progenitor cells in mice. J Clin Invest (2009) 119:1888-98. doi:10.1172/JCI37028

35. Gu D, Sarvetnick N. A transgenic model for studying islet development. Recent Prog Horm Res (1994) 49:161-5.

36. Kayali AG, Van Gunst K, Campbell IL, Stotland A, Kritzik M, Liu G, et al. The stromal cell-derived factor-1alpha/CXCR4 ligand-receptor axis is critical for progenitor survival and migration in the pancreas. J Cell Biol (2003) 163:859-69. doi:10.1083/jcb.200304153

37. Kume S. Stem-cell-based approaches for regenerative medicine. Dev Growth Differ (2005) 47:393-402. doi:10.1111/j.1440-169X.2005.00814.x

38. Yano T, Liu Z, Donovan J, Thomas MK, Habener JF. Stromal cell derived factor-1 (SDF-1)/CXCL12 attenuates diabetes in mice and promotes pancreatic beta-cell survival by activation of the prosurvival kinase Akt. Diabetes (2007) 56:2946-57. doi:10.2337/db07-0291

39. LiuZ,HabenerJF.Stromal cell-derived factor-1 promotes survival of pancreaticbeta cells by the stabilisation of beta-catenin and activation of transcription factor 7 -like 2 (TCF7L2). Diabetologia (2009) 52:1589-98. doi:10.1007/s00125-009-1384-х

40. Liu Z, Stanojevic V, Avadhani S, Yano T, Habener JF. Stromal cell-derived factor-1 (SDF-1)/chemokine (C-X-C motif) receptor 4 (CXCR4) axis activation induces intra-islet glucagon-like peptide-1 (GLP-1) production and enhances beta cell survival. Diabetologia (2011) 54:2067-76. doi:10.1007/s00125-011-2181-x

41. Grdovic N, Dinic S, Mihailovic M, Uskokovic A, Jovanovic JA, Poznanovic G, et al. CXC chemokine ligand 12 protects pancreatic beta-cells from necrosis through Akt kinase-mediated modulation of poly(ADP-ribose) polymerase-1 activity. PLoS One (2014) 9:e101172. doi:10.1371/journal.pone.0101172

42. Ha HC, Snyder SH. Poly(ADP-ribose) polymerase is a mediator of necrotic cell death by ATP depletion. Proc Natl Acad Sci US A (1999) 96:13978-82. doi:10.1073/ pnas.96.24.13978

43. Virag L, Szabo C. The therapeutic potential of poly(ADP-ribose) polymerase inhibitors. Pharmacol Rev (2002) 54:375-429. doi:10.1124/pr.54.3.375

44. Markovic J, Uskokovic A, Grdovic N, Dinic S, Mihailovic M, Jovanovic JA, et al. Identification of transcription factors involved in the transcriptional regulation of the CXCL12 gene in rat pancreatic insulinoma Rin-5F cell line. Biochem Cell Biol (2015) 93:54-62. doi:10.1139/bcb-2014-0104

45. Feng G, Hao D, Chai J. Processing of CXCL12 impedes the recruitment of endothelial progenitor cells in diabetic wound healing. FEBS $J$ (2014) 281:5054-62. doi:10.1111/febs.13043

46. Gallagher KA, Liu ZJ, Xiao M, Chen H, Goldstein LJ, Buerk DG, et al. Diabetic impairments in NO-mediated endothelial progenitor cell mobilization and homing are reversed by hyperoxia and SDF-1 alpha. J Clin Invest (2007) 117:1249-59. doi:10.1172/JCI29710

47. Ceradini DJ, Kulkarni AR, Callaghan MJ, Tepper OM, Bastidas N, Kleinman ME, et al. Progenitor cell trafficking is regulated by hypoxic gradients through HIF-1 induction of SDF-1. Nat Med (2004) 10:858-64. doi:10.1038/nm1075

48. Butler JM, Guthrie SM, Koc M, Afzal A, Caballero S, Brooks HL, et al. SDF-1 is both necessary and sufficient to promote proliferative retinopathy. J Clin Invest (2005) 115:86-93. doi:10.1172/JCI22869

49. Togel F, Isaac J, Hu Z, Weiss K, Westenfelder C. Renal SDF-1 signals mobilization and homing of CXCR4-positive cells to the kidney after ischemic injury. Kidney Int (2005) 67:1772-84. doi:10.1111/j.1523-1755.2005.00275.x

50. Sayyed SG, Hagele H, Kulkarni OP, Endlich K, Segerer S, Eulberg D, et al. Podocytes produce homeostatic chemokine stromal cell-derived factor-1/ CXCL12, which contributes to glomerulosclerosis, podocyte loss and albuminuria in a mouse model of type 2 diabetes. Diabetologia (2009) 52:2445-54. doi:10.1007/s00125-009-1493-6 
51. Darisipudi MN, Kulkarni OP, Sayyed SG, Ryu M, Migliorini A, Sagrinati C, et al. Dual blockade of the homeostatic chemokine CXCL12 and the proinflammatory chemokine CCL2 has additive protective effects on diabetic kidney disease. Am J Pathol (2011) 179:116-24. doi:10.1016/j.ajpath.2011.03.004

52. Matheus AS, Tannus LR, Cobas RA, Palma CC, Negrato CA, Gomes MB. Impact of diabetes on cardiovascular disease: an update. Int J Hypertens (2013) 2013:653789. doi: $10.1155 / 2013 / 653789$

53. Doring Y, Pawig L, Weber C, Noels H. The CXCL12/CXCR4 chemokine ligand/receptor axis in cardiovascular disease. Front Physiol (2014) 5:212. doi:10.3389/fphys.2014.00212

54. Farouk SS, Rader DJ, Reilly MP, Mehta NN. CXCL12: a new player in coronary disease identified through human genetics. Trends Cardiovasc Med (2010) 20:204-9. doi:10.1016/j.tcm.2011.08.002

55. Decaillot FM, Kazmi MA, Lin Y, Ray-Saha S, Sakmar TP, Sachdev P. CXCR7/ CXCR4 heterodimer constitutively recruits beta-arrestin to enhance cell migration. J Biol Chem (2011) 286:32188-97. doi:10.1074/jbc.M111.277038

56. Naumann U, Cameroni E, Pruenster M, Mahabaleshwar H, Raz E, Zerwes HG, et al. CXCR7 functions as a scavenger for CXCL12 and CXCL11. PLoS One (2010) 5:e9175. doi:10.1371/journal.pone.0009175
57. Bernhagen J, Krohn R, Lue H, Gregory JL, Zernecke A, Koenen RR, et al. MIF is a noncognate ligand of CXC chemokine receptors in inflammatory and atherogenic cell recruitment. Nat Med (2007) 13:587-96. doi:10.1038/ nm1567

58. Tanegashima K, Suzuki K, Nakayama Y, Tsuji K, Shigenaga A, Otaka A, et al. CXCL14 is a natural inhibitor of the CXCL12-CXCR4 signaling axis. FEBS Lett (2013) 587:1731-5. doi:10.1016/j.febslet.2013.04.046

Conflict of Interest Statement: The authors declare that the research was conducted in the absence of any commercial or financial relationships that could be construed as a potential conflict of interest.

Copyright $\odot 2015$ Vidaković, Grdović, Dinić, Mihailović, Uskoković and Arambašić Jovanović. This is an open-access article distributed under the terms of the Creative Commons Attribution License (CC BY). The use, distribution or reproduction in other forums is permitted, provided the original author(s) or licensor are credited and that the original publication in this journal is cited, in accordance with accepted academic practice. No use, distribution or reproduction is permitted which does not comply with these terms. 